\title{
Reprobación y sátira del gramático en las letras áureas II. Textos literarios, principios del siglo XVII
}

\author{
José Enrique López Martínez \\ Universitat de València \\ Departamento de Filología Española \\ Facultad de Filología, Traducción y Comunicación \\ Av. Blasco Ibáñez, 32 \\ 46010 Valencia \\ q13puma@hotmail.com
}

[La Perinola, (Issn: 1138-6363), 22, 2018, pp. 141-163]

DOI: $10.15581 / 017.22 .141-163$

En el último tercio del siglo Xvi, se produjo en España un debate cada vez más complejo en contra de la figura del gramático como había sido propuesta idealmente y llevada a cabo desde hacía más de un siglo por autores como Antonio de Nebrija, Juan de Brocar o Lorenzo Palmireno, siguiendo la estela del humanismo italiano. Textos como los Diálogos de Arce de Otálora, y especialmente el Examen de ingenios (1575) y los Diálogos familiares para la agricultura cristiana (1589) constituyeron el inicio de una serie de tratados que recuperaron y difundieron en lengua castellana varios de los argumentos que desde distintos ámbitos, como la teología, se habían vertido repetidamente contra los humanistas; $y$, además, poco a poco los fueron enriqueciendo con nuevos elementos que ampliaron la reprobación de la gramática frente al resto de las ciencias, apoyados en el estoicismo, la teoría humoral o la filosofía moral cristiana, entre otros sistemas de pensamiento. En tal momento, y a diferencia también de lo que había ocurrido en las décadas anteriores, este proceso pronto comenzó a ser secundado desde las propias aulas universitarias, como se observa en la Minerva (1589) y la traducción del Enchiridion (1600) del Brocense, el Discurso del humanista (1600) de Baltasar de Céspedes, o la Elocuencia española, de Jiménez Patón (1604). Los argumentos fueron diversos y aplicados por cada autor con diferentes intenciones: acusaciones de soberbia y arrogancia dirigidas contra el gramático, que pasaron de lo general a tener una justificación en la oposición entre memoria y entendimiento en Huarte de San Juan; sátiras por la propensión a pelear con otros filólogos o por su presunta maledicencia; distinción cualitativa entre el conocimiento lingüístico y los saberes verdaderos, serios, graves, como la 
virtud para la filosofía moral, donde también aparece con frecuencia el comentario despectivo sobre las minucias gramaticales que preocupan al humanista; y muy particularmente la acusación de intrusismo, de que el gramático no puede y no debe acercarse a ninguna otra disciplina fuera de su estricto campo elemental y técnico de trabajo, idea que tendrá mayores implicaciones cuando sea asumida por personalidades como el Brocense, Céspedes y Jiménez Patón ${ }^{1}$. Aquel conjunto de obras y el debate que produjeron dará origen en los primeros años del siglo XVII a una abundante representación satírica y burlesca del gramático o humanista, que recogerá en textos literarios varios de los principales argumentos desarrollados por esos tratadistas y añadirá otros, en ocasiones con la misma base ideológica, y en ocasiones ampliando la crítica hasta descripciones y caricaturas con simple valor cómico ${ }^{2}$. Por la mayor parte, y más allá de los rasgos individuales, el corpus que formarán estas expresiones literarias confirmará lo mismo que la tratadística castellana que las antecedió: el abandono casi definitivo de la propuesta humanística de la grammatica como fundamento y centro de todos los saberes, y la limitación del grammaticus a los principios elementales de la lengua, del humanista a la mera erudición sobre textos literarios de la Antigüedad grecolatina, sin más implicaciones para las ciencias vivas coetáneas. Fue la restitución de la gramática al nivel más bajo del sistema

1. Sobre este proceso, aquí brevemente resumido, y la delimitación del periodo y corpus señalado, ver López Martínez (en prensa), con más referencias bibliográficas sobre el desarrollo del humanismo a lo largo del siglo xvi. Remito a esas páginas también para aclaraciones adicionales sobre los términos humanista, gramático, pedante y crítico, aplicados en concreto al filólogo humanista, y especialmente sobre algunos de los antecedentes más importantes de los distintos motivos de esta sátira en la literatura castellana. Como indico ahí, aquellos tratadistas de finales del xvi y otros anteriores desarrollaron importantes ataques al humanismo, al tiempo de aceptar parcialmente algunos de sus principios (la defensa del gramático como censor de todo tipo de textos, en Arce de Otálora, o la noción histórica de la lengua latina, en Baltasar de Céspedes, por ejemplo), incluido el uso o defensa del patrimonio cultural de la Antigüedad en varios de ellos. El análisis que propongo en ambos trabajos se centra en textos en lengua castellana, y se apoya especialmente en las aportaciones de Rico, 1978, sobre Nebrija y el primer humanismo.

2. Espino Martín, 2002, ha dedicado un trabajo al análisis del personaje del dómine que aparece en algunos textos doctrinales y narrativos de los siglos XVI al XVIII, desde los Diálogos de la educación de Luis Vives hasta el Dómine don Supino de Vegas y Quintano, pasando por el Buscón de Quevedo y el fray Gerundio Campazas del padre Isla. Como es sabido, personajes como el dómine Cabra constituyen figuras grotescas y ridículas, a cuenta incluso de su apariencia física, que poco o nada tienen que ver con críticas serias a los métodos de docencia o a su importancia social; todo ello se reduce, cuando se menciona, a su consabida ignorancia de la lengua latina o mal gusto para escoger autores clásicos. Alguno de esos rasgos aparecerá en los gramáticos satirizados por los ingenios barrocos aquí comentados, pero en realidad lo que se presentará en sus páginas será de una naturaleza bien distinta: una mayor consciencia de la implicación de la gramática como ciencia del conocimiento, y una afirmación de su inferioridad frente a otras disciplinas científicas o artísticas. Las representaciones cómicas de dómines y preceptores latinistas también se observa en textos teatrales como en El dómine Lucas, de Lope, o Marta la piadosa y Ventura te dé Dios, de Tirso. 
de conocimientos en el Renacimiento tardío y el Barroco ${ }^{3}$. Al parecer, la trasposición de ese debate al ámbito de la literatura de creación ocurrió de forma amplia entre el primer y el segundo decenio del xvII, al mismo tiempo que escritores como Quevedo y Suárez de Figueroa hacían sendas aportaciones al debate sobre la gramática dentro del ámbito de la tratadística en la España defendida (ca. 1609), el primero, y la Plaza universal de todas las ciencias, el segundo (1615). En este estudio analizaré el conjunto de pasajes satíricos contra el gramático o el humanista en textos literarios de los primeros decenios del siglo xvII, con la intención de mostrar su desarrollo cronológico y su relación de continuidad con aquel conjunto mencionado de tratados que difundió más ampliamente los ataques al humanismo en el tramo final del siglo XvI.

Varios años antes del primer momento de eclosión de sátiras literarias contra los gramáticos, que será encabezado por Salas Barbadillo a partir del segundo decenio del xvII, vale la pena registrar un caso temprano de aparición de esa crítica particular, coetáneo a los textos de Huarte y Pineda que impulsan los nuevos debates en lengua castellana contra el humanismo: un breve fragmento de Las lágrimas de Angélica, de Luis Barahona de Soto (1587)4. La que sería la más antigua sátira poética contra el gramático que apreciamos en nuestra literatura aparece en el canto 8 de esta obra, el relato de la visita del personaje de Zenagrio al hada Gleoricia. Ahí se nos cuenta que, después de recorrer la selva alegórica de la fama, y tras la historia de la dama lasciva, el hada muestra al protagonista un catálogo de personajes arrogantes y que pretenden la fama por malos medios, encabezado precisamente por gramáticos, retóricos y oradores. Al igual que en las acusaciones vertidas por numerosos autores sobre la pedantería del gramático, primordialmente desde la posición de la filosofía moral y acaso también por influencia de

3. Como señalamos en el trabajo anterior, en la segunda mitad del xvi parece haberse extendido el uso de humanista para designar solo al erudito o conocedor de textos grecolatinos y antigüedades, sin implicar necesariamente la ciencia de la gramática, pero nunca sustituyó del todo su uso para designar también al gramático especializado, tanto en defensores como en detractores. En tal sentido, lo que se observa en el Diálogo de Baltasar de Céspedes es una propuesta de institucionalizar al humanista, partiendo de aquella noción, como simple comentarista de textos literarios clásicos, en detrimento de la figura del gramático que proponían Antonio y otros autores.

4. Rico, 1978, pp. 90-95, ofreció asimismo un panorama breve sobre el mal gramático como personaje de textos literarios europeos desde las primeras décadas del xvi. Aquel corpus inicia en textos como el Conflictus Thaliae o el Synnodus de Erasmo, y pasa por las Epistolae obscurorum uirorum, T. Folengo y Rabelais; y aun antes de ellos, la sátira de los gramáticos que aparece en el Carón de Pontano (1469). Pero se trata de una sátira de muy diferente sentido a la que veremos un siglo después en la España áurea: aquella es la que los humanistas dirigen contra los gramáticos bárbaros que siguen aceptando los viejos métodos de concepción y enseñanza del latín, sin un conocimiento directo de los textos antiguos; en tanto que, como señalamos, la de los autores barrocos, derivada especialmente de la tratadística del xvi y de la confrontación científico-dogmática que los anima, surge de la desaprobación del gramático frente a la teología y los otros saberes considerados más importantes. 
la relectura renacentista de Séneca ${ }^{5}$, aquí los gramáticos son incluidos por causa de su presunta soberbia, uno de los pilares principales de la repulsa del gramático en ambos siglos, y sobre todo por sus escrúpulos en cuestiones lingüísticas muy menores respecto al presunto valor verdadero de los autores graves:

Tanto del soez gramático arrogante, que porque punta y coma sus diciones, y ordena lo de otras para adelante, no estima los gravísimos varones; tanto orador, retórico abundante, hinchado con hacer declamaciones, que en más estima su vaniloquencia que de otros la riqueza ni la ciencia ${ }^{6}$.

Idea que se extiende versos más adelante también a historiadores, dialécticos y humanistas, que aúnan todos tres el motivo -asignado con frecuencia solo a los gramáticos- de la propensión a las disputas inútiles o sobre asuntos sin verdadera importancia, noción derivada principalmente de la condena que se hacía desde las posturas de la filosofía moral y el estoicismo:

$\mathrm{Y}$ tanto historiador, tanto humanista, que tras sus buenas letras va perdido, tanto escudriñador y gran cronista, que muere por saber quién otro ha sido, y al fin tanto dialéctico y sofista, que va cazando moscas sin sentido, con silogismos vanos y aparentes,

5. En España hubo un creciente interés en la obra de Séneca y la relectura del estoicismo a partir del siglo xv desde distintos campos de la filosofía moral; en ese contexto tuvo gran importancia la traducción de Alonso de Cartagena, publicada varias veces hasta bien entrado el siglo xvi, de las Epístolas morales a Lucilio, y especialmente de la Epistola 88 sobre las artes liberales, que ofrecía a los detractores de la gramática una amplia crítica al conjunto de saberes frente a la búsqueda y ejercicio de la virtud (por ejemplo, la idea de la vanidad de conocimiento humano y la soberbia que puede producir, y también la condena de las «minucias» del gramático); sobre esta temprana traducción y el contexto de recepción de Séneca en España entre los siglos xv y xvi, Blüher (1983, pp. 113-155).

6. Por otra parte, cabe también mencionar aquí otro interesante fragmento poético de La mexicana, texto coetáneo de Lobo Lasso de la Vega (1588), muy cercano en sentido al de Barahona. En él acusa asimismo la envidia y maledicencia del gramático a través de dos ejemplos famosos de la antigüedad: «Vio a Zoilo, que estaba maltratando / a Homero con palabras injuriosas; / vio a Dídimo seis libros hojeando, / copiosos de razones afrentosas, / con que al gran Cicerón iba culpando / sus obras detrayendo tan famosas; / Salustio y Cicerón vio competían / y que epístolas feas se escribían» (Lobo Lasso de la Vega, 1970, p. 163). Recuérdese que Dídimo ya aparecía satirizado en la Epístola 88 de Séneca por su obra prolífica al tiempo que inútil, y que fue también incluido con el mismo sentido en las críticas a los gramáticos de los Diálogos de Arce de Otálora; aunque aquí más bien Lobo se hace eco de otros prejuicios más largamente asentados y coloca a Dídimo solo como maldiciente. 
y con su disputar cansa las gentes (Barahona, Lágrimas, p. 390)?

Tras esta temprana muestra de sátira contra los gramáticos, no parece haberse repetido este motivo con frecuencia en textos literarios durante alrededor de veinte años, en los que sin embargo la tratadística dio pasos muy importantes en ese sentido en la obra de los gramáticos de la universidad de Salamanca y otros autores ya comentados. Es a finales del primer decenio del siglo que algunos ingenios satíricos, claramente familiarizados con las disputas entonces recientes contra los filólogos en España y Europa, comienzan a centrar su atención en ellos para reproducir las mismas sátiras en obras de ficción. En tal sentido, tiene un lugar fundamental la obra de Alonso Jerónimo de Salas Barbadillo, quien iniciará plenamente esta amplia tradición en la literatura barroca desde sus primeras producciones, y será además el autor que en más ocasiones acudirá a este tema específico. El madrileño también se distinguirá al ampliar las diatribas contra aquellos personajes con el recurso a una mayor diversidad de motivos satíricos que los que se habían desarrollado en los debates científicos del siglo anterior.

La primera pieza de Salas en aparecer en la imprenta, de las que nos conciernen, es La ingeniosa Elena (1614), que presenta la más temprana de sus sátiras del gramático en un relato intercalado en la narración principal titulado El pretendiente discreto ${ }^{8}$. En la introducción del personaje principal, Salas incluye unas líneas críticas en las que en principio parte de una sátira diferente, que tiene antecedentes muy antiguos y aparecerá con frecuencia en su literatura, la de la falsa ostentación de sabiduría ${ }^{9}$; pero de inmediato pasa a referirse, sin mencionarlo, al gram-

7. Para entender mejor la postura que expresa aquí Barahona, cabe tener presente que en tal catálogo de arrogantes incluye también a geómetras, arquitectos, contadores, astrólogos o adivinos; es decir, parece unir las profesiones menores y las condenadas por la Iglesia, y distinguirlas de las profesiones graves como el derecho, la medicina y, por supuesto, la teología. En su glosa posterior al canto completo, Barahona lo concibe enteramente en función de la enseñanza general sobre el vicio de la vanagloria. Barahona distingue entre gramáticos y humanistas porque entiende a estos últimos como lectores eruditos de textos grecolatinos, noción bien asentada ya en este momento del siglo xvi.

8. Esta novela fue parte de los numerosos textos con los que Salas amplió la primera versión de su relato, aparecida sin su autorización en Zaragoza en 1612 con el título de La hija de Celestina. A manera de antecedente (aunque no hay coincidencia en los argumentos específicos), cabe señalar que Salas había escrito, en 1604, un soneto preliminar a la Elocuencia española de Jiménez Patón, en la cual, recordemos, también aparecían unas líneas en contra del intrusismo del gramático y del retórico en otras disciplinas.

9. Es un tema cercano, aunque no idéntico, a la perspectiva estoica y de filosofía moral cristiana que acusaba la vacuidad del saber humano frente a la virtud o el conocimiento de Dios. Solo por dar una breve muestra castellana del riquísimo tema del falso sabio, o de la mera vanidad de ostentar tal título, cabe recordar lo que decía Pérez de Moya hacia 1585: «No son muy diferentes de estos los que parecen a Pireneo, que tienta de encerrar y forzar a las Musas en su palacio, cuando con hermosas librerías y con apariencias de sabios procuran hacer entender que poseen a las Musas, que son las ciencias, las cuales no tienen más que en los libros, porque no han bebido como debieran para ser 
maticus, a través del recuerdo de los mismos defectos que hemos escuchado en los tratadistas del xvi: la pedantería, el ignorar la verdadera esencia del conocimiento; y por primera vez en esta forma específica en un texto literario, la propensión a pelear con otros colegas, casi siempre por cuestiones nimias o absurdas, que será como veremos una de las ideas más recurrentes de Salas en este contexto ${ }^{10}$ :

Solo Federico, caballero noble y de pocos años [...] amante de la soledad, aborrecía la corte; y retirado en un castillo suyo se entregaba todo a la filosofía, recreándose en sus estudios, sin aspirar a más pretensión que a la del título de sabio, que procuraba merecelle por su trabajo y perpetua asistencia sobre los libros, y no con los ardides y estratagemas de que hoy se valen estos doctos de tropelía y estudiosos de invención, que con solo tener una ciencia de librero, que es saber los títulos de los libros, y de lo que tratan por mayor y en qué partes, y cuántas veces han sido impresos, quieren competir y sobre ello desnudan las espadas y las lenguas con aquellos que han puesto la mano en el corazón de las ciencias y no hay rincón ni parte tan secreta en ellas que no le hayan visitado ${ }^{11}$. Este género de gentes es insufrible y dura en su conversación: blasonan de que entienden y tratan con tanta elegancia la lengua griega como Demóstenes y no saben la castellana con ser su propia natural y materna; hínchanse con su latín y desvanécense porque conocen a dónde viene bien el paréntesis y a dónde el interrogante; traen en la fraldiquera un Horacio o un Marcial roto, porque deben de ser

tenidos por lo que quieren de la fuente Castalia) (Filosofía secreta de la gentilidad, p. 438). Salas repite la idea en La sabia Flora malsabidilla (1621), donde expresa con más claridad el ánimo moralista que también impulsa sus diatribas contra los gramáticos: «Mirad, señora: un marido tan barbón se hace despreciable con lo mismo que él piensa que se adquiere veneración; descuídase de su familia, y estase siempre en su bien encuadernada librería; sin ser letrado profesa letras, y no entiende todas las que le componen. El sabio de estos tiempos ha de estudiar en las malicias de que la corrompida edad es autor, no para ejercitarlas, sino para prevenir la enmienda en las que caen debajo de su gobierno. Aquel para mí es hombre entendido que tiene caudal propio, y no el que mendiga de los libros lo que, por no entenderlo, no sabe ejecutarlo. Por lo menos sus amigos los filósofos morales no han podido rescatarle de los dientes vulgares que tanto muerden su fama» (Salas, Obras, vol. 1, p. 353).

10. En los tratados del seiscientos, el motivo de la pelea de gramáticos había aparecido tempranamente en los Coloquios de Arce de Otálora, y varias décadas después solo en la Plaza de Suárez de Figueroa, en ambos casos como un recuerdo erudito de fuentes de la Antigüedad clásica más que como argumento científico o referencia de la realidad coetánea, como sí ocurría con otros argumentos contra el filólogo.

11. El motivo de la ciencia de librero, de la vana erudición libresca, es habitual en la filosofía moral, y por lo que toca a nuestro tema está también relacionado con la idea de la lectura metafórica o parabólica, como decía Pineda, de la que el gramático es incapaz; más ampliamente, con la noción de que este no puede acceder a los verdaderos conocimientos de los textos desde su campo lingüístico específico. Sin embargo, cabe notar que es invención de Salas el aplicarlo a los gramáticos, ya que en tal forma no ha aparecido en ningún otro autor hasta este momento. En tal sentido, la sátira de Salas da un resultado interesantísimo, ya que varía el catálogo de nimiedades filológicas, reales o burlescas, que se atribuyen desde todos los campos a los gramáticos, para presentarlo también en términos específicamente vinculados al mundo de la imprenta. El mismo tema satírico de saber los títulos de libros será explorado años después por Gabriel del Corral en el epigrama 10 de La Cintia de Aranjuez (1629), “De los provectos y graves». 
los libros de estos de la condición que el manto y beca de colegial, que mientras más gastado y rompido representa mayor autoridad. Hacen visajes cuando hablan y quieren que hasta el viento pasajero suspenda el paso y les escuche; y cuando oyen a los otros se divierten con artificio, como haciendo desprecio de lo que se trata y procurando dar a entender que es humilde materia para sus oídos, perdiendo muchas veces, por esta arrogancia ignorante, infinitas cosas que, si las escucharan, descubrieran en ellas doctrina y utilidad científica (pp. 114-115) ${ }^{12}$.

En estas mismas líneas, Salas presenta también por primera vez en su obra y acaso en la literatura castellana otros rasgos satíricos diferentes a los de la tratadística anterior: la acusación de que aquellos humanistas vanos no saben hablar bien la lengua castellana, y el motivo ridículo de llevar siempre algún autor clásico en la faldriquera, ideas que se repetirán en muchas más de sus sátiras y descripciones burlescas. Cabe notar también que aquí el autor no solo retoma el tópico del gramático arrogante, sino que le da un desarrollo más extenso y complejo que varios de los antecedentes del XVI, acumulando diferentes motivos en torno a aquella idea central, y también dando un carácter ligeramente más violento a la supuesta tendencia a discutir de los gramáticos, que continuará ampliándose en la literatura de Salas en textos posteriores.

$\mathrm{Al}$ mismo tiempo que el pasaje comentado, Salas acude a la sátira del crítico en otro pasaje de su colección de novelas Corrección de vicios, publicada en $1615^{13}$. Al inicio de cada capítulo de esta obra, el personaje satírico de «Boca de todas verdades» ofrece distintos discursos sobre temas específicos, a manera de marco narrativo común para el conjunto de novelas breves que la conforman; el que encabeza el capítulo 8 versa sobre el arte poética, en el que el censor, «venerando a los eminentes en ella, hace juego de aquellos que son plebe y vulgo de la poesía». En medio de tal discurso aparece una extensa descripción sobre un tipo particular de poeta, en la que el autor se centra en criticar dos aspectos específicos: las glosas torpes de versos, y las malas traducciones poéticas, pero para ello acude a motivos que están vinculados a la sátira tradicional del filólogo, como la preocupación u obsesión por aspectos

12. Los pasajes que recogeremos aquí son aquellos en que Salas se refiere, en nuestra opinión, al filólogo especializado. Pero varios de los motivos que vemos en esta serie de diatribas también son aplicados con frecuencia a otro tipo de personajes de su literatura: críticos o censuradores de escritos ajenos, soberbios y maledicentes, sin mayor caracterización como gramáticos o filólogos. Es el caso del Censor lego que aparece en la segunda parte de El caballero puntual (1619), cap. viI, y años después el del personaje del perro poeta Fisgarroa, en la fábula de La peregrinación sabia, censurador de todos los autores de la academia de los animales. Es un célebre pasaje en el que numerosos estudiosos han reconocido una alusión a Cristóbal Suárez de Figueroa.

13. Aunque aparecida aquel año, esta obra fue presentada por Salas junto con $L a$ ingeniosa Elena y otros tres libros para solicitar un privilegio conjunto en diciembre de 1613. Sin embargo, es también la única de las cinco de la que consta una fecha precisa de escritura, ya que una indicación expresa y otros indicios señalan que fue terminada en agosto de 1612; véase López Martínez, 2014. 
gramaticales menores y la propensión a pelear. A ello, Salas añade otro motivo asimismo relacionado con el quehacer del filólogo pero que apenas ha aparecido en las reprobaciones del gramático, la tendencia a la enmienda de los textos ${ }^{14}$. Así, esta burla, desarrollada dentro del campo de la creación literaria, se dirige a partes iguales a ambos personajes, poetas y gramáticos ${ }^{15}$ :

Otros hay, gente condenada y de almas perversas: estos son unos hombres que, permitiendo crecer la barba, dejan su rostro con tanta espesura que se pudiera perder en él el Marqués de Mantua, gramáticos rebeldes y contumaces que sobre la averiguación de si es adverbio o vocativo, sacan a sus abuelos de la sepultura y maltratan la honra de sus mujeres. Estos tales son unos poetas que no escriben cosa que enteramente sea suya y sirven de echar a perder obras ajenas, porque como ellos no tengan bastante caudal en el ingenio para concebir y sacar a luz, cuando ven el papel ajeno le muerden. Allí le dan el bocado y le arrancan el adjetivo a la oración y, poniendo otro en su lugar, dicen que es palabra de más significación y propiedad para la materia de que trata. En otra parte mudan el verbo, aquí el nombre y acullá el artículo, sin atreverse a borrar la copla entera porque no saben hacer otra para dejar en su lugar, y con esto son poetas de los de guárdenos Dios. Y lo que acertó el primero, en vez de enmendarlo, lo arroja el segundo en el infierno, pues de suerte lo dispone que es fuerza condenarle por mal poeta para siempre ${ }^{16}$. Otros hay que traducen, diciendo mal en castellano lo que

14. Como hemos visto en otras obras, fue habitual la reprobación del gramático humanista a través de la burla de su interés por cuestiones como la puntuación, la ortografía o la pronunciación, en vez de ocuparse del sentido último y amplio de los textos, pero no el motivo específico de las enmiendas incorrectas como aquí las describe Salas. Prácticamente en el mismo momento que nuestro autor, Suárez de Figueroa reivindicará la labor de enmienda del filólogo en su Plaza universal (1615), al exponer la definición de la gramática idiétera: «censurando todo género de escritores, reconociendo lo que es legítimo de cada uno, reprobando lo espurio, enmendando lo depravado y restituyendo a los verdaderos autores lo que es suyo» (Suárez, Plaza universal, vol. 2, p. 1000).

15. Por otra parte, tampoco parece haber sido frecuente la asociación de los malos traductores con la sátira del filólogo, aunque autores como Baltasar de Céspedes, en el Discurso del humanista («De la acción de las cosas»), efectivamente señalaban la traducción como una de las tareas propias del gramático. Salas ya había sugerido, con menos detalle, esta estampa burlesca del poeta que glosa o copia, y que reproduce asimismo vicios del pedante, en otro pasaje de La ingeniosa Elena: «Ya sé que me miráis todos a las manos para saber por qué puerta sale el que dio libertad a las bien castigadas matronas. ¿Quién duda que algún poeta de cartapacio - de estos que piensan que porque trasladaron el soneto y romance de su vecino en papel que era suyo, escrito de su letra y con pluma que les costó sus dineros, que pueden canonizar el trabajo por propio- se arma contra mí reprehendiéndome la flojedad de mi ingenio con mucha aspereza, pues se durmió en cosa que tanto importa? Sosiégate, pedante, y no te levantes tan presto de la silla, que ya soy con tu pensamiento y no te dejaré en este particular sin llenarte los vacíos» (Salas, La ingeniosa Elena, p. 112). Esta crítica anticipada al gramático como forma de defender el escrito propio aparecerá más ampliamente desarrollada al final del tratado de antigüedades sobre los juegos Días geniales o lúdricos, de Rodrigo Caro (ca. 1626).

16. En la comedia Los prodigios de amor, publicada al final de la segunda parte de El caballero puntual (1619), Salas incluye otra breve descripción de los gramáticos, para censurar su excesiva atención a glosas, definiciones y enigmas: "Bien sé qué fortuna es. / Celio: iOh, señor, no definamos! / Bien con lo que fuese estamos, / pesadumbre no me 
el otro bien en latín o toscano. Y hacen esto con tanta dureza y escabrosa disposición que viene a estar el concepto más escuro en español que en latín, pareciendo aquel más lenguaje de jerigonza que frasis poética. Traen ordinariamente consigo un Marcial en la faltriquera, y cada uno dice que si no es él nadie hasta entonces ha entendido las dificultades de aquel sutil poeta; y a no estar el otro en el infierno, que es lugar donde no pasan burlas, se riyera de ellos, porque tiene cosas que solo el que las dijo las entendió y aquellos a quien él reveló su pensamiento, si con alguno usó de esta cortesía, que yo no estuve entonces en Roma y no podré decir lo que hubo en ello (Salas, Obras, vol. 1, pp. 216-217) ${ }^{17}$.

De esta forma, los gramáticos poetas, o poetas gramáticos, serán acusados de arrogancia, como en la tradición inmediata anterior, y de su habitual disposición a las peleas, además de repetirse el motivo del Marcial en la faldriquera que también apareció en El pretendiente discreto. Pero más allá de la combinación con la figura del poeta sin natural, Salas ofrece otras variaciones complejas sobre aquellos elementos básicos de la sátira antihumanista que seguirán enriqueciendo el personaje barroco del gramático literario. Acaso por simple cruce fugaz con el recuerdo de los personajes burlescos del médico y el letrado que entonces abundan en la literatura castellana, o del poeta pobre de la tradición clásica, Salas presenta ahora a un poeta desaliñado o que quiere hacer valer su sabiduría a través de su barba, como los otros con sus grandes librerías. Respecto al gramático, más importante será la crítica de la pretensión de ser el único estudioso en haber comprendido a un determinado autor u obra, que podría ser un recuerdo también de sátiras clásicas o de algunos argumentos de la tratadística, pero que en todo caso será otra de las ideas más recurrentes de Salas ${ }^{18}$; y aunque en relación con la traducción,

des, / porque las definiciones, / enimas y cosi cosas, / y cierto modo de glosas, / es muy para pedantones» (Salas, Obras, vol. 2, p. 385).

17. En varios autores, los argumentos centenarios en contra de los gramáticos, junto con la crítica más específica de los malos latinistas, se trasladó al ámbito de la poesía para censurar a los poetas oscuros y latinizantes; de ahí, a su vez, terminarían abultando también las sátiras en contra del gongorismo en el segundo decenio del xvII. Salas parece tener aquí el objetivo claro de los poetas con veleidades filológicas y a los propios filólogos; pero unos argumentos muy parecidos utilizaría en la misma época Tirso para asociar a pedantes y críticos con gongoristas, en la barca del «Parnaso crítico» de los Cigarrales de Toledo (publicado en 1634, aunque con aprobaciones de 1621): “Causó novedad el traje de los nuevos dogmatizantes porque las coronas de la ingrata ninfa no ceñían sus sienes como se acostumbraba, sino sus cinturas. Pudo ser por llamar a los de esta facultad (que tan mal se dan a entender por palabras) bachilleres de estómago [...] Pues, si toda su elegancia consiste en anteponer y posponer vocablos, entretejiendo verbos entre adjetivos y sustantivos - que también tiene Apolo sus pedantes-, del mismo modo les pareció podían critiquizar sus vestidos, posponiendo los unos y anteponiendo los otros. Hasta la misma barca los imitaba, porque bogaba al revés, la popa adelante y la proa atrás, con no poca risa de los que entendieron la satírica navegación. Parece que venían los afectados académicos interpretándose a sí mismos unos con otros con escandalosa confusión de todos» (Tirso, Cigarrales, pp. 197-198).

18. Recordemos que Huarte de San Juan y otros autores señalaban la soberbia del gramático que pretendía haber entendido pasajes de la Biblia y de otros textos sagrados 
la idea de oscurecer a los autores originales recuperará el tema, sugerido también en la España defendida de Quevedo, de que los filólogos entorpecen con sus abundantes comentarios y glosas los textos que deberían declarar. Pero por encima de todo ello, cabe señalar que estos motivos convergen en una idea general de mucho interés para Salas: la de la incapacidad de estos profesionales para escribir ellos mismos un verso o una obra literaria como la que pretenden editar, interpretar, o glosar; es decir, que la censura contra el mal gramático y los diversos defectos de su oficio estará aquí vinculada predominantemente con la reivindicación de la propia creación poética ${ }^{19}$.

Al lado de páginas de vocación más seria, como las que hasta ahora hemos visto, Salas también desarrolló la sátira del gramático en composiciones festivas, con intenciones más jocosas que morales, pero basándose en la mayor parte de los casos en acusaciones como las referidas y retomando sus motivos específicos. Sucede así en un fragmento del entremés El tribunal de los majaderos, incluido en la colección de novelas La casa del placer honesto $(1620)^{20}$. Un gramático será precisamente el primero de los tipos cuya causa juzgarán los dos funcionarios de este tribunal satírico, que confirmará siempre la sentencia de majaderos a todos los personajes ridículos que acuden en serie ante ellos. Aplicada específicamente a un profesor de Escuelas de Salamanca, la breve residencia de este gramático soberbio vuelve sobre la sátira de ser el único en haber entendido un pasaje, como antes los poetas críticos, para continuar con la burla de su vano desprecio por todos y de la ostentación falsa de sabiduría, aquí en la forma específica de la compra de títulos universitarios:

Ganasa Por este memorial refiere un hombre que ha leído seis años en Escuelas, y que porque decía en cualquier cosa “este lugar yo solo le he entendido» -algo vanaglorioso y atrevidotu alguacil denunció, y el juez que tienes

mejor que los santos o los teólogos, como además parece haber ocurrido en el caso de las arrogancias atribuidas al Brocense en su proceso inquisitorial. Por otra parte, la expresión de ser el único en comprender un pasaje podría estar relacionada con la frase atribuida a Palemón, en el De Grammaticis et Rhetoribus de Suetonio, xxıII, de que con él habían nacido y con él morirían las letras, recordada en la tradición hispana al menos por Arce de Otálora.

19. También Céspedes nos puede dar un referente comparativo para la idea que expresa aquí Salas, porque el maestro de Salamanca ofrecía en la misma sección del Discurso sobre la acción una larga argumentación en la que, por una parte, disculpaba al gramático especializado de la obligación de escribir poesía, y al tiempo aseguraba que ningún gran poeta podía serlo sin ser un consumado humanista, en la acepción erudita y no filológica de este término. En un sentido contrario se ubicará aquí Salas, para quien el filólogo representa la antítesis exacta del poeta en tanto creador, e incluso en tanto intérprete de la poesía.

20. Aunque se presenta como un entremés, y tiene la métrica habitual que estas formas de teatro breve presentan a partir de los años veinte del siglo, el texto no tuvo ninguna vida escénica, como sucedió con todo el teatro de Salas Barbadillo; se trata de piezas que únicamente se publicaron como obras literarias destinadas a la lectura. 


\begin{tabular}{ll} 
& Él apela del auto y te suplica... \\
Monseñor & iOh, qué gran majadero! ¿Que replica? \\
& Confirmo la sentencia, y más le mando: \\
& que majadero público se llame, \\
& cosa que en esta edad es poco infame; \\
& que traiga las insignias descubiertas. \\
& De majadero le ordenad, hermano... \\
GANASA & ¿Cuáles son? \\
Monseñor & \multicolumn{1}{c}{ Tener poca cortesía, } \\
& y a todos despreciar con fantasía. \\
& Decilde más: que no sienta desprecios, \\
& que es la mayor fineza de los necios. \\
GANASA & ¿Así tratas, señor, a un licenciado \\
& que fue por su dinero gradüado? \\
Monseñor & Si como su dinero, en esa ciencia, \\
& gradüado le hubiera suficiencia, \\
& estimárale yo, sirviente mío; \\
& pero si compró el título de sabio, \\
& que también se ha hecho hoy mercadería \\
& intitularse la sabiduría, \\
& ¿queréis que estime yo por estudiante \\
& al que fue de las ciencias trujamante, \\
& y que, yendo a la feria de los grados, \\
& el mejor escogió por su dinero, \\
& feriando el ser letrado y majadero? \\
& (Salas, El tribunal de los majaderos, p. 258)
\end{tabular}

Esta misma vena burlesca, que repite motivos de los debates serios pero que se dirige más a un resultado cómico que a una afirmación moral o científica, se confirma en una de las epístolas satíricas incluidas en el relato de Don Diego de Noche (1623) 22 ; en ella, después de las censuras sobre las disputas de filólogos que Salas ha repetido en sus primeras sátiras, progresivamente más violentas que las estampas de los tratadistas anteriores, el madrileño llega a describir directamente una pelea a golpes entre dos pedantes ridículos. Aunque observamos de nuevo la burla a la pretensión de ser el único que ha entendido a un autor, la pedantería, e incluso el cruce con la figura del preceptor de escuelas, lo cierto es que esos elementos comienzan a aparecer como lugares comunes al lado de otros juegos de lenguaje con mero valor cómico, rematada en la animalización jocosa de estos personajes:

21. En el conjunto de sátiras contra gramáticos de Salas apenas hay alusiones posibles a personajes reales, pero tal vez en el fondo de esta escena tenemos un recuerdo de los conocidos procesos inquisitoriales contra los catedráticos de Salamanca ocurridos en el último tercio del siglo xvi (fray Luis de León, Martínez de Cantalapiedra, Grajal, el Brocense).

22. Aunque publicado en esta fecha, el libro había recibido las aprobaciones en julio de 1621 . 


\section{EpÍ́sTOLA SEGUNDA}

A un amigo pedante que se trató mal de palabra con otro gramático sobre la inteligencia de un lugar de Virgilio

Pierdes tu honra por defender la de Virgilio, que está en el infierno. Dime, ¿qué honra puede tener un condenado? Préciaste mucho de ser solo el que le ha entendido, que inútil fuera tu trabajo. A tanto llegó la pasión entre ti y Doristo, que os distes de puñadas en una librería pública, cosa que a ninguno pareció mal, porque como los gramáticos se están siempre [con] niños, nadie se admira de que no olviden sus acciones. Esta pendencia os hizo a los dos profesos en la pedantería, porque semejante desatino solo pudiera hacerle dos pedantes confirmados en su necedad. Él [te] hizo sangre en la boca, que defendiste a tu amigo Virgilio, ya que no con la sangre de tus brazos, con la de tus muelas. Tirástele tú una coz: tú anduviste más gramático, porque todos son bestias. Dios me libre de entrambos, que al fin el uno da manotadas y el otro coces (Salas, Don Diego de Noche, fols. 38v-39r).

Pero estos juegos de paradojas y asociaciones burlescas, tan del gusto del autor especialmente en sus epístolas satíricas, como veremos de nuevo más adelante, no desplazan nunca su interés teórico por la crítica de los gramáticos. Pocos años después de publicar la epístola la epístola de Don Diego de Noche, Salas debió de escribir el texto titulado Coronas del Parnaso que constituirá el marco introductorio al libro misceláneo del mismo nombre, publicado de manera póstuma en $1635^{23}$. Se trata de una sátira parnasiana que, entre otros muchos motivos, incluye parcialmente la guerra de los poetas, como en el Viaje del Parnaso cervantino y otras obras. Al inicio de esa sección del relato se representa un gran tumulto ante el palacio de Apolo, que supondrá el preludio de la batalla naval poética entre los preclaros ingenios españoles y la turba de poetastros que pretende asaltar el Parnaso; tumulto ocasionado al final, a pesar del enorme temor creado en toda la corte, por un insignificante personaje ridículo, un gramaticón pedante que aparece también con las muelas en sangre, como el defensor de Virgilio de la epístola. Aunque Salas repetirá aquí la mayoría de estampas y censuras que hemos visto, desarrolla en particular dos motivos diferentes a los que no había puesto atención hasta este momento pero que tienen una larga tradición en los ataques al humanismo del siglo xvI: el gramático que con soberbia se atreve a corregir a los grandes autores de la Antigüedad ${ }^{24}$, y el que pretende saberlo todo de todas las disciplinas, la censura sobre la impo-

23. Entre otros rasgos, un fragmento del texto apunta al año de 1626: «Al fin, el quinto año de este dichoso imperio [de Felipe IV], salieron de España para el Parnaso, cuando entraba el abril en ella, tres no menos floridos ingenios...) (Salas, Coronas, fols. 2v-3r).

24. Esa postura se puede poner en relación especial con la que expresaba el Brocense en su glosa al texto del Enchiridion, ya en el marco del resurgimiento barroco del estoicismo en España, donde señalaba que «para obrar se han de leer los buenos libros [como los de Aristóteles], que no para levantar sobre ellos frívolas disputas»; y también con las múltiples censuras y catálogos de gramáticos maledicentes que atacan sin razón a los autores, como se observa en Arce de Otálora, en la España defendida de Quevedo, y en la Plaza universal de Suárez de Figueroa. 
sibilidad de realización del humanista como doctor de todas las ciencias, por recordar la expresión de Nebrija, como apreciamos a finales del XVI en la obra del Brocense, Céspedes y Jiménez Patón; es decir, es uno de los pasajes más claramente antihumanistas de toda la literatura de Salas, y al tiempo uno de los pocos suyos también en que se da voz al propio gramático como personaje literario:

Tantos aparatos quedaron ridículos, porque [Apolo] vio que, cercado de los soldados de la guarda, subía un capigorrón, necio origen de aquella tempestad jocosa. Traía los guantes puestos, los bigotes levantados, los ojos encendidos, las muelas bañadas en sangre, el cuello hecho hilazas, y un Terencio en la mano, rompidas algunas hojas. Por la relación que se hizo, pareció que aquel era un gramático pedante natural de Calabria, el más soberbio de todos los de su profesión, porque decía haber venido al Parnaso a corregir todas las ciencias y facultades, y dar luz a la ignorancia de Apolo. Los oyentes, que justamente le tuvieron por loco, se riyeron al principio de esta proposición. Prosiguieron con algunas preguntas, y en las respuestas conocieron que era gramático, con que disculparon su pedante soberbia, tan natural en todos. Sacó el libro de Terencio, y dijo que aquel era el sabio de los sabios, y que solo él le había entendido. Ya en esta ocasión era mucho el pueblo que le había cercado, que dando sobre él con una y otra ola le traían a la redonda y le decían: «Ríndete, pedante». Y él respondía: «Ni al mismo Apolo me rendiré». Estas fueron las palabras que causaron los ridículos recelos de Apolo, y que no quedaron sin castigo, pues le dieron tantas coces y puñadas, que la guarda más bajó a rescatalle del furor popular que a prendelle. Allí, entre los pies de todos, con blasfema obstinación prosiguía, y se afirmaba en que ni al mismo Apolo se rendiría. Fue tan ciego en su frenesí que cuando se vio con él rostro a rostro le habló con igual o mayor libertad. Apretaba las manos y los dientes y decía: «Yo soy el doctísimo César Clodio Rufino, padre de las ciencias y corrector de ellas» ${ }^{25}$. Dos efetos sintió Apolo en sí, uno de corrimiento por el mucho miedo que había concebido, y otro de gozo, por haber visto el amor y fidelidad de los súbditos, pues se irritaron contra aquel miserable, con ser conocidamente loco, porque le perdía el respeto. Agradeció al pueblo su demostración fiel, aunque imprudente, y mandó a un soldado que tuviese en su casa preso aquel pedante hasta que se tomase resolución en el castigo que se le había de dar, que fue bien ajustado a su culpa, como se dirá en otro lugar, por ser más propio (Salas, Coronas, fols. 15-15v).

Después de esa extensa presentación, el resto del relato menipeo continuará por diversas secciones en las que, entre otras cosas, se describirá a grandes rasgos la organización de la armada de poetas que defenderá el Parnaso de los legos romancistas; pero, justo antes de re-

25. No sé si es exagerado identificar a este misterioso Claudio César Rufino con el no menos misterioso gramático del siglo v, Rufino de Antioquía, aunque aquí Salas lo hace calabrés. Especialmente apunta hacia él la mención de Terencio, ya que en efecto el antioquense escribió un compendio In metra terentiana. De todas formas, más que esa posible alusión concreta, en este Rufino debe haber también un recuerdo general de la frase atribuida por Suetonio al gramático Palemón. 
presentarnos el inicio de esa batalla, Salas recupera a este pedante del inicio para incluirlo, escarmentado por sus castigos, entre la canalla que va en las galeras de la armada poética. Además de los rasgos específicos con los que se satiriza al Rufino y demás críticos, la burla de la necia intención de corregir a Apolo reitera simbólicamente la idea de la inferioridad del gramático respecto al poeta y también la sátira de las enmiendas filológicas que había presentado en Corrección de vicios:

Veíanse entre esta miserable canalla algunos gramáticos pedantes, porque con sacrílego atrevimiento habían intentado enmendar muchos lugares a Homero y a Virgilio. Uno, entre muchos, tenía una mordaza en la boca, en pena de su blasfemia, porque dijo con vanagloria y presunción: «Yo he nacido, yo, para castigar los errores del padre de los poetas latinos». César Clodio Rufino, aquel gramaticón que los días pasados había sido el escándalo de Palacio, aquel que puso a la majestad de Apolo en tanto cuidado y desasosiego, acompañaba a los demás en su miseria y calamidad, y ya más humilde y modesto decía: “Vosotros los que me oís, escarmentados en mi desdicha, aprended a obedecer los preceptos de Apolo y no irritéis la ira de tan grande majestad y poder» (Salas, Coronas, fol. 26v) ${ }^{26}$.

Este relato satírico será incluido por Salas al frente de la extensa miscelánea que terminará de preparar en octubre de 1630, y que titulará también Coronas del Parnaso, aunque no será publicada hasta cinco años más tarde, pocos días después de la muerte del prosista madrileño. En esta colección, que incluye secciones de varios géneros literarios, Salas recoge por última vez la sátira del gramático en un pasaje del primero de los dos epistolarios jocosos incluidos en el volumen, y lo hace nuevamente en su forma más burlesca, como en la epístola comentada de Don Diego de Noche $e^{27}$. Sin embargo, aquí la intención burlesca se alejará todavía más de las condenas al filólogo arraigadas en el pensamiento español, para mostrarlo solo en una perspectiva grotesca a partir de la cual se elaboran paradojas y juegos con el motivo del vino y la lengua latina, en los que solo se conservará una vaga alusión a la soberbia del gramático; en cualquier caso, es también la última de las aportaciones

26. Más allá de la sátira general sobre la arrogancia del gramático, estos pasajes sobre las enmiendas de errores en autores como Horacio y Virgilio podría ser también un recuerdo de los obtrectatores de la Antigüedad, los gramáticos célebres por sus duros comentarios de los grandes escritores, como Zoilo, a quien ya vimos en el pasaje de Lobo Lasso de la Vega citado al inicio. Compárese también con el siguiente texto de Antonio de Toledo (1590): «Tuvo Homero a un Zoilo, y Horacio a un Nevio, y Virgilio a un Pierio y otros que de lo mejor de él sacaban ocasiones de calumniar» («A los lectores» en Álava de Viamont, El perfecto capitán, fol. $+4 \mathrm{v})$.

27. En Coronas está incluida la fábula de La peregrinación sabia, en la que aparece el poeta envidioso Fisgarroa ya señalado; pero en la misma obra, justo antes de aquel pasaje, otro de los concurrentes a la academia de los animales también describe brevemente a uno de nuestros personajes satíricos: «el tordo era un mal gramático pedante, hablador importuno y muy preciado de retórico, siendo más verboso que elocuente» (Salas, $L a$ peregrinación sabia, p. 44). 
de Salas al desarrollo de este personaje satírico y a la difusión de esa censura generalizada en la literatura española del xvII:

\section{A Demetrio, gramático soberbio, y Que Se deJaba Vencer del Vino}

Con justa causa presume vuestra merced de sabio, señor Demetrio, porque si es verdadero el refrán que dice «Que mucho sabe la zorra, pero que más sabe quien la toma», si vuestra merced toma cada día tantas, no solo es sabio, sino la misma sabiduría. En todo es verdadero gramático, porque siempre anda declinando con la cabeza, y conjugando con las vasijas, y apenas con la cantimplora en la mano es la persona que hace, cuando luego cercado de los muchachos se pasa a ser la persona que padece. Mientras más bebe se enfurece más, y habla mejor latín, tanto, que por vuestra merced se ha mudado el proverbio, porque ya no se dice «Bebe como un tudesco», sino «Bebe como un latino». Antes de agora los hijos de los poderosos apenas querían estudiar la lengua latina por su pereza, y desde hoy en adelante será vanidad, porque dirán que no quieren aprender una lengua que las zorras hablan. Como vuestra merced más bien sabe, esta palabra, mamona, significa en latín la 'riqueza', de quien es el eco mona; de donde se sigue que ya que vuestra merced no puede conseguirla, se consuela con el eco. Quien le ve a vuestra merced tan soberbio dirá que es el viento; quien le huele tan vinoso presumirá que es el fuego; y la verdad es que lo uno con lo otro se enciende, porque la soberbia escurece el juicio, y en estando este añublado, es fácil rodar a mayor vicio. Suele vuestra merced decir por gracia que los buenos bebedores no solo gozan del oro potable, sino de los rubíes potables, porque el buen vino blanco tiene el color del oro, y el aloque el de los rubíes. Tal vez recita versos latinos, y salen tan embriagados de su boca que con tener el menor de ellos tantos pies, apenas se pueden tener en ellos. Tome vuestra merced mi consejo y enmiéndese. Mas vuestra merced es más amigo de tomarse del vino que de tomar consejos (Salas, Coronas, fols. 153-153v).

Alrededor de este mismo momento de finales de los años treinta, Quevedo por su parte vuelve a ofrecer una serie importante de sátiras contra el gramático en varios de los textos que recupera para la imprenta o que escribe en sus años de madurez, y que en todo caso se relacionan claramente tanto con las ideas que había desarrollado en la España defendida como con la parte final del desarrollo de su pensamiento estoico ${ }^{28}$. La primera de esas nuevas manifestaciones públicas

28. Como indicaremos, los estudiosos de la obra de Quevedo sitúan algunos de los textos comentados, o al menos sus primeras versiones, en años cercanos a la escritura de la España defendida; pero los consideramos aquí principalmente porque, a diferencia de aquel tratado, son piezas que Quevedo decide publicar en un mismo momento de finales de la tercera década del siglo. A propósito de los tratados del xvi, especialmente el Pinciano y Palatino de Arce de Otálora y los Diálogos familiares de Juan de Pineda, señalamos ya una posible influencia en el pensamiento español de la obra de Séneca y particularmente de las Epístolas morales a Lucilio. No descartamos que el poeta madrileño conociera aquellos textos concretos y el conjunto de la tratadística en que se inscriben, pero su caso particular se explica por un nuevo movimiento estoico europeo, representado por Lipsio y por la oleada de ediciones de la obra de Séneca producidas a finales del xvi; y asimismo español, que habría tenido su origen posiblemente en la traducción 
contra el gramático humanista aparecerá en un breve pasaje de El sueño del infierno / Las zahúrdas de Plutón ${ }^{29}$. Al igual que en la España defendida, aunque aparentemente sin las mismas preocupaciones nacionales que afirma de forma expresa ahí, Quevedo recuerda al final del Sueño a José Escalígero como gramático hereje y maledicente, entre otros teólogos y gramáticos protestantes, y vuelve a menospreciar la demasiada agudeza y letras frente a la verdad de la religión:

Volvime a un lado y vi todos los herejes de ahora, y topé con Maniqueo. ¡Oh, qué vi de calvinistas arañando a Calvino!, y entre estos estaba el principal Josefo Escalígero, por tener su punta de ateísta y ser tan blasfemo, deslenguado y vano y sin juicio. Al cabo estaba el maldito Lutero, hinchado como un sapo y blasfemando, y Melanctón comiéndose las manos tras sus herejías. Estaba el renegado Beza, maestro de Ginebra, leyendo sentado en cátreda de pestilencia. Y allí lloré viendo el Enrico Estéfano. Preguntele no sé qué de la lengua griega, y estaba tal la suya que no pudo responderme sino con bramidos.

- Espántome, Enrico, de que supieses nada. ¿De qué te aprovecharon tus letras y agudeza? (Quevedo, Sueños, p. 481) ${ }^{30}$.

Esta breve escena de protestantes condenados en el infierno es la segunda y última de las sátiras que implican a gramáticos históricos en textos de Quevedo ${ }^{31}$. Pero también en esta época tardía el poeta se hizo

del Enchiridion del Brocense (obra que Quevedo usará para su versión poética). Véase el estudio de Blüher (1983) sobre las distintas etapas de recepción de Séneca en España en los siglos XVI y XVII, y sobre la influencia de Justo Lipsio en la obra de Quevedo, con abundante bibliografía (especialmente pp. 390-472). Blüher considera la versión temprana de la Doctrina moral, que sitúa sin dudas en 1612, como la primera etapa del pensamiento neoestoico del poeta; y después una segunda etapa, marcada por cierto deseo de consuelo a partir del segundo exilio del autor en 1628, expresada en textos como la nueva versión de la Doctrina moral (La cuna y la sepultura), De los remedios de cualquier fortuna (1632), o el conjunto de textos y traducciones que forman la Doctrina estoica (1635).

29. Este texto se publicó con el primer título en los Sueños y discursos, en marzo de 1627, y con el segundo en los Juguetes de la niñez, en marzo de 1631 (primera aprobación de agosto de 1629), con variantes en el texto. Sin embargo, en las dos impresiones se incluyen la dedicatoria y final firmados por Quevedo en abril y mayo de 1608, un año antes de comenzar a escribir la España defendida.

30. Cito el texto de los Juguetes. La principal diferencia con respecto a la versión anterior es que en ella el protagonista no dirige la última frase a Estéfano, sino a Lutero, tras un largo discurso sobre sus errores teológicos. Véase el comentario de este pasaje en Lida, 2016, pp. 76-78, donde lo pone en relación con otro ataque contra los dos Escalígeros en las cartas de Quevedo, propiciado por los juicios negativos de José sobre los autores hispanolatinos y su desprecio general contra España, aspecto que sin embargo no se hace explícito en el Sueño. Esta crítica es más clara en un pasaje anterior de la misma obra, donde a pesar de recordar a Escalígero entre los presuntos autores de libros de hechicería aprovecha para denostar sus juicios literarios: «Julio César Escalígero se estaba atormentando por otro lado en sus Exercitaciones, mientras pensaba las desvergonzadas mentiras que escribió de Homero y los testimonios que le levantó por levantar a Virgilio aras, hecho idólatra de Marón» (Quevedo, Sueños, p. 476).

31. Quevedo se distingue de Salas Barbadillo precisamente en dirigir sus censuras a gramáticos reales, en tanto que el segundo siempre se referirá a personajes genéricos, sin 
eco de varios de los motivos cómicos que hemos visto en la obra de Salas Barbadillo para apoyar parte de su configuración de La culta latiniparla $(1631)^{32}$. Aunque se trata de una sátira dirigida por momentos contra los poetas culteranos y los conversadores latinizantes, los textos que anteceden al propio «Disparatario» de términos cultos presentan una caricatura de la dama latiniparla que se basa claramente en las de los filólogos que han precedido de forma abundante este momento de la literatura áurea, como el recuerdo del autor en la faldriquera y la vana pretensión de sabiduría, de los abundantes e inútiles comentos, e incluso del propio Antonio ${ }^{33}$ :

Siendo vuestra merced más conocida por los circunloquios que por los moños, de tan lindas sinécdoques y cacofonías, y tan airosa de hipérboles y tan nebrisense de palabras, que tiene vuestra merced más nominativos que galanes, y siendo la dama de más arte (de Antonio) que se ha visto, más merlincocaya que Merlín, obligación le corre al más perito (y no es fruta) de encimarla en los precipicios inaccesos de otra, si no tan sidérea estimación aplaudida, si bien de menos trisulca pena (Plauto sea sordo), dirigiéndola este candil para andar prosas lúgubres. Es vuestra merced adivinanza perene, y tiene enigma lluvia, y puede a su menor visita examinar ordenantes.

Es conveniente que las que siguen esta doctrina y chirrían confusiones, lo que antes, cuando eran legas, fue: «Cierta persona dijo esto», “González dijo estotro», «bien dijo don Juan», hoy sea: «Platón enseña», «dogma es del Estagirita», "así lo razona Homero». En las visitas, al levantarse, echará de menos un Plutarco que se le cayó de la manga; tendrá críticos de faldriquera como güeros, y autores de falda como perrillos; y enviará a pedir por la vecindad prestado un Tertuliano para cierta advertencia. Idiotas y plagiarios y magistas son otro tanto oro para decir mal de los modernos. Y cuando las otras digan

alusiones a filólogos específicos. Sin embargo, más allá de la acusación de herejía y algún motivo menor, como la preferencia por Virgilio frente a Homero, lo cierto es que en la mayor parte de sus numerosos ataques a los Escalígeros y otros humanistas extranjeros Quevedo no mencionará apenas otras razones más específicas para su crítica; será en otros textos donde sí recordará los motivos de la soberbia y la falta de capacidad para la interpretación simbólica que son comunes en la reprobación hispánica del gramático, aunque ya sin destinatarios concretos.

32. No se conoce la fecha de su escritura. El año anterior de 1630 habían aparecido dos primeras impresiones, aunque con un texto más breve y numerosas variantes, con el título de Catecismo de vocablos para instruir a las damas hembrilatinas; véase el estudio de García Valdés (Quevedo, Prosa festiva, pp. 112-114).

33. Véase lo indicado en la nota 17. La sátira a los escritores, o conversadores, que acudían a falsos latines o a interpolaciones impertinentes en castellano tiene una larguísima tradición, anterior a las críticas a los poetas cultos y al gongorismo. Los humanistas mismos ya habían señalado este defecto: valgan como ejemplo las objeciones que el Brocense incluyó al final de su Minerva, o las palabras de Simón Abril (Gramática griega, fol. 2): «De manera que estas lenguas antiguas muy grande bien es que se estudien para entender lo que hombres dotos hijos naturales de ellas escribieron en ellas; pero usallas ni hablando ni escribiendo casi ya no se puede hacer sin destruillas. A lo menos el hablallas las destruye, y el escribir en ellas no las enriquece, y en muchos las estraga y saca de sus quicios». Pero, como sucedió con otros motivos, a los propios gramáticos también se les acusó de este vicio, como recogía Suárez en el Discurso iv de la Plaza universal con estampas burlescas de la misma factura que la Culta quevediana. 
que hacen vainicas, si la preguntaren qué hace, diga que comentarios, notas y escolios, y sean a Plinio, si fuere posible. Tenga achaques de varias lecciones; $y$ si estuviere preñada, se le antojen Escalígeros crudos o Lipsios en almíbar. Y a las joyeras les pregunte si tienen cintas de Musato o tocas de Casaubón, que son buenos nombres (Quevedo, Prosa festiva, pp. 444-445, 448-449).

Fuera de esta descripción burlesca, en los textos publicados por el poeta hacia los años treinta vuelve sobre las críticas serias contra la filología en sendos textos dedicados a la filosofía estoica, aunque con parámetros distintos a los de sus críticas a los gramáticos protestantes. El primero de ellos es probablemente La cuna y la sepultura (1634), ${ }^{34}$ tratado de doctrina moral en cuyo capítulo iv se ocupa del desengaño general de los conocimientos humanos. En esa diatriba dedica un pasaje específico a los gramáticos como ejemplo de arrogancia y pretensión de sabiduría, en donde recupera la sátira del sentido literal, el desprecio que ostentan aquellos contra todos los demás, y la ignorancia de lenguas ajenas y propias, para concluir con la afirmación de Dios como verdad última, de la misma forma que lo hemos visto en críticas antihumanistas de autores como Juan de Pineda:

Ello bien podemos nosotros dejar de confesar que somos inorantes, pero dejar de serlo no podemos. Toda nuestra sabiduría es presunción acreditada de la ignorancia de los otros. iQué soberbio está el gramático con la inteligencia literal de las voces, que ni sabe qué significan ni conoce el uso propio de ellas en las lenguas peregrinas! iCon qué ceño y desprecio mira a los demás el que dice que no hay cosa dificultosa para él en la lengua hebrea y griega, siendo verdad que la propia, que naturaleza le enseñó, no la sabe, y que no puede hablar ni escribir en ella sin reprehensión! Cierto es que todos estos hombres saben estas cosas sobre su palabra, y no saben más de lo que o la cortesía o la inocencia ajena les creyere. Y demos que sabes todas esas lenguas y que tienes de memoria todos los libros que en ellas hay escritos: ¿por eso piensas que sabes algo? Pues engáñaste, que ni aquellos supieron qué enseñarte, ni tú puedes saber lo que ellos no alcanzaron. Sospecharían mejor en las cosas que tú y estarían en la menos dañosa opinión; pero otra cosa no le es concedida al hombre, porque la sabiduría verdadera está en la verdad, y la verdad es una sola, y esa verdad una es Dios solo, que por eso

34. Aunque no se trata de prosa de ficción, incluyo aquí este texto por su fecha de publicación, más cercana a este momento de renovada crítica contra los gramáticos en la obra del poeta que a la tratadística de inicios de siglo. El original de esta edición había sido aprobado en junio de 1633, con una dedicatoria firmada por Quevedo el mes anterior de mayo; pero al igual que la Culta, esta obra había aparecido en una versión diferente en dos impresiones de 1630, con el título de Doctrina moral del conocimiento propio. Debido a una carta a Tamayo de Vargas y una anotación incluida en uno de los testimonios manuscritos, algunos estudiosos han sugerido que el texto pudo ser escrito ya en noviembre de 1612, a pesar de su publicación tardía; véase también el análisis de García Valdés (Quevedo, La cuna y la sepultura, pp. 11-39). Esta fecha se correspondería con las mismas que se han sugerido para España defendida, con la que coindice en algunos argumentos, pero esta datación temprana no ha sido comprobada con mayores elementos. 
le llaman Dios verdadero; y fuera de Él todo es opinión, y los más cuerdos sospechan (Quevedo, La cuna y la sepultura, pp. 112-113) ${ }^{35}$.

El mismo tono y contenido se desarrolla en las líneas del Epicteto (1635), versión métrica del Manual del filósofo griego hecha de forma cercanísima sobre la traducción del Brocense ${ }^{36}$; como aquel, Quevedo repite las ideas del filósofo acerca del vano conocimiento libresco, en favor de una sabiduría que se encamine y traduzca en la virtud, como lo habían acusado asimismo otros filósofos morales castellanos:

Si alguno, porque entiende

los libros de Crisipo y los tratados de Aristóteles, doctos y admirados, se muestra grave y tiene fantasía, dirás entre ti mismo: «Si Aristóteles no hubiera escrito obscuro y en estilo tan duro, este, que ignora cosas de importancia, no tuviera soberbia ni arrogancia».

Empero yo pregunto:

¿qué son las cosas que saber deseo

cuando estos libros leo?

Digo que deseara

entender, si pudiera,

a la naturaleza, y la siguiera

para entenderla y ser en ella diestro;

pido y busco maestro

que me la enseñe; dice que en Crisipo

se puede esto aprender; yo me anticipo,

léole, y no le entiendo;

busco quien le interprete y le declare,

logro esta diligencia,

hallo intérprete, y hallo que la ciencia

no es bastante saberla sin obrarla;

porque si yo me ocupo en estudiarla,

35. Este párrafo no tiene variaciones en respecto a la primera versión de la Doctrina moral (Quevedo, La cuna y la sepultura, pp. 194-195). Por otra parte, más adelante Quevedo se dirige también en general a las universidades, a las que ahora acusa de varias cosas que antes, en la España defendida, condenaba en las universidades extranjeras específicamente: «Qué ocupadas están las universidades en enseñar retórica, dialéctica y lógica, todas artes para saber decir bien! iY qué cosa tan culpable es que no haya cátedras de saber hacer nada bien, y donde se enseñe! Los maestros, según esto, enseñan lo que no saben, y los discípulos aprenden lo que no les importa, y así nadie hace lo que había de hacer» (Quevedo, La cuna y la sepultura, p. 117). Sobre otros aspectos del estoicismo de Quevedo en este texto, Blüher (1983, pp. 427-447).

36. La traducción del Brocense se publicó primero en 1600, y fue reimpresa en 1612, fecha que algunos especialistas en Quevedo han sugerido al menos como la del inicio de su adaptación en verso. El volumen del Epicteto y Focílides apareció en marzo de 1635, con aprobaciones de octubre de 1634, pero véanse las consideraciones de Blüher (1983, p. 461) sobre las fechas de los textos de ese impreso. 


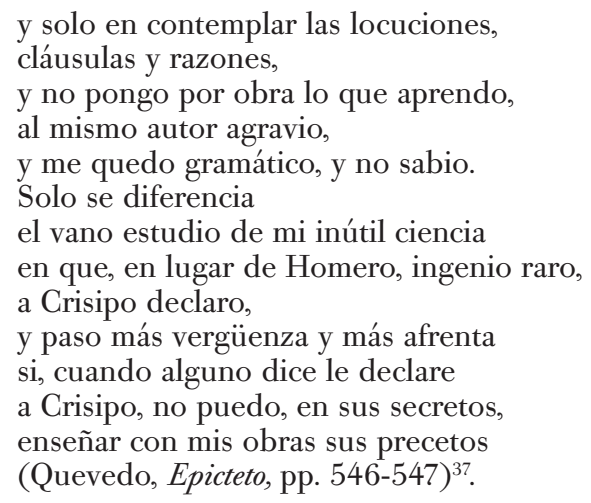

De esta forma, Salas Barbadillo y Quevedo se distinguirán claramente, de entre las generaciones de ingenios activos a principios del siglo XVII, en la sátira contra los gramáticos humanistas en la forma en la que tales críticas se habían ido desarrollando desde el último tercio del siglo anterior, aunque solo se trate de un breve reflejo de los complejos debates que llevaban más de un siglo redefiniendo el pensamiento y la educación en la Península; y que al lado de ello, también reconfigurarán esa sátira en forma de literatura burlesca, en estampas con intención jocosa fuera de las preocupaciones intelectuales que animaron sus ata-

37. Véase el comentario al original del Brocense en López Martínez (en prensa). Además de los antecedentes en torno a la figura del gramático, y otros de su tratamiento de la filosofía estoica, Quevedo había manifestado ideas cercanas sobre la relación entre conocimiento humano y virtud cristiana, por ejemplo, en su Vida de santo Tomás de Villanueva (1620): «Este es el nacimiento maravilloso de nuestro Santo [...] Esta, la mocedad asegurada, y que conociendo lo que valen las horas, hizo logro de los instantes y supo poner precio al tiempo. Estos fueron los estudios encaminados a verdadera sabiduría, sin presunción ni vanidad, que tuvieron por premio y dieron por fruto al santo estudiante conocimiento tan severo, que supo despreciar los títulos vulgares de las letras y poner en la sagrada religión de san Agustín en salvo sus vigilias y trabajos» (Quevedo, Vida, pp. 43-44). Es la misma perspectiva que se desarrolló en autores como Juan de Pineda y fray José de Sigüenza, este último también en tratando de vidas de religiosos eminentes. A pesar de los abundantes estudios sobre el estoicismo en España, y en particular sobre las aportaciones en tal sentido de determinados autores como el Brocense o Quevedo, no tengo constancia de que se haya llevado a cabo un análisis sobre la forma en que el estoicismo y el escepticismo, junto con otras corrientes de pensamiento, pudieron también determinar la jerarquía del sistema de conocimientos de los siglos XVI y XVII en el que la gramática fue destinada a los estratos más bajos. Sobre Quevedo, cabe citar el comentario de Blüher (1983, p. 431), extensible al conjunto de la obra del autor: «Pero ya una primera mirada revela que lo que a Quevedo le interesa no es la problemática inherente a la teoría del conocimiento, como era el caso del científico Sanches, que entendía el problema crítico como una premisa de un nuevo método para encontrar la verdad, sino exclusivamente el aspecto moral de la cuestión. En el fondo, el escepticismo revestía importancia para él solo en cuanto que de aquel se deducía la incapacidad cognoscitiva del hombre. Todo conocimiento del hombre en este mundo, se dice en la Doctrina moral, está expuesto a la duda y no es más que mera conjetura. La verdad está solo en Dios y no se hace accesible al hombre hasta después de la muerte...». 
ques serios al humanismo. De aquellos tratados médicos, filosóficos o retóricos, nuestros dos escritores recuperarán principalmente el motivo de la soberbia del crítico, y de su incapacidad para la interpretación parabólica, ambos con el interés claro de supeditar el saber gramático a las premisas de la filosofía moral, y en el caso de Salas, con particular atención también a la reivindicación de la creación poética como un ámbito ajeno e inaccesible para el filólogo. De esos textos también tomarán la forma de la sátira, las invectivas breves sin apenas construcción y desarrollo de personajes novelescos, con lo que se pierde mucho en complejidad literaria pero se abunda en la exposición de argumentos y por lo tanto de implicaciones teóricas contra los gramáticos. No son estas las muestras finales del debate: como vimos, en el ámbito de los tratados tanto la defensa como la degradación del pedante continuó mucho más allá de los primeros textos del siglo xviı en las que veíamos las primeras aportaciones de Quevedo y Suárez de Figueroa. También en las formas literarias la sátira del gramático continuó floreciendo más allá de los textos de madurez de Salas y Quevedo, apenas respondida por algunos defensores del ya viejo ideal del humanista como conocedor de todo tipo de textos, y de la gramática como fundamento para el dominio sin límites de todas las disciplinas ${ }^{38}$. Pero la persistencia del debate y la constatación de tales defensores no contradice la existencia de un ambiente generalizado de menosprecio del gramático - no del preceptor escolar, sino del filólogo especializado que fueron Nebrija, Erasmo y el mismo Brocense- que ya no le restituiría nunca más en los espacios que había alcanzado en la universidad y en la vida intelectual en la primera mitad del siglo xvi. Es la derrota final del humanismo, o el nacimiento de uno específicamente español como suponen algunos especialistas, pero que no parece ser tal sino acaso una reducción de todos los fundamentos centrales de la propuesta de Antonio al conocimiento técnico de la lengua y al estudio literario de los autores grecolatinos, sobre todo

38. La consideración de Quevedo como humanista, que se mantiene entre numerosos estudiosos modernos, debería al menos matizarse y ponerse en relación con la noción de gramática de Valla y Nebrija, y también con sus juicios negativos sobre el gramático que se verifican a lo largo de toda su trayectoria. Porque lo que muestra el autor español es una coincidencia amplia con los argumentos en contra de esa gramática humanista gestados desde el pensamiento religioso español y la filosofía moral del siglo xvi. No obsta para ello el interés de Quevedo por diversas actividades intelectuales como la historia, la historia de la lengua, la crítica textual, las etimologías, el comentario filológico de textos, o por el conocimiento de los autores grecolatinos. Nada de ello define por sí solo al gramático humanista, y numerosos detractores de la gramática también tuvieron incursiones en aquellas materias, como Arce de Otálora o Juan de Pineda. Las diatribas de Quevedo contra el gramático y contra gramáticos históricos se inscriben en la misma línea de pensamiento antihumanista que animó numerosas páginas de Huarte de San Juan, Pineda, Céspedes, y otros autores. Véase sobre ello el comentario a la España defendida en López Martínez (en prensa), y la opinión de Raimundo Lida (2016, p. 85) sobre la evolución de lo que llama el «desordenado humanismo» de Quevedo. Por otra parte, acerca de su abandono al parecer definitivo del estoicismo a favor de una doctrina puramente cristiana en sus años de vejez - concretamente a partir de 1635-, Blüher, 1983, pp. 472-479. 
poetas, en detrimento de toda posible incursión de la gramática, como conocimiento histórico del lenguaje, en cualquier otra ciencia ${ }^{39}$.

\section{Bibliografía}

Álava de Viamont, Diego, El perfecto capitán, Madrid, Pedro Madrigal, 1590.

Barahona de Soto, Luis, Las lágrimas de Angélica, ed. José Lara Garrido, Madrid, Cátedra, 1981.

Blüher, Karl A., Séneca en España. Investigaciones sobre la recepción de Séneca en España desde el siglo XIII hasta el siglo XVII, Madrid, Gredos, 1983.

Espino Martín, Javier, «El humanismo docente: gramáticos y dómines en Luis Vives, Francisco de Quevedo, José Francisco de Isla y Manuel de Vegas y Quintano», en Humanismo y pervivencia del mundo clásico. Homenaje al profesor Antonio Fontán, Alcañíz, Instituto de Estudios Humanísticos, 2002, vol. 5, pp. 2457-2468.

Lida, Raimundo, Prosas de Quevedo, Madrid, Centro para la Edición de los Clásicos Españoles, 2016.

Lobo Lasso de la Vega, Gabriel, La Mexicana, ed. José Amor y Vázquez, Madrid, Atlas, 1970.

López Martínez, José Enrique, “Corrección de vicios, de Salas Barbadillo, y la primera etapa de la novela corta española», Lejana. Revista crítica de narrativa breve, 7, 2014, s. p.

López Martínez, José Enrique, «Reprobación y sátira del gramático en las letras áureas. I. Diálogos y tratados, fines del siglo xvI», Revista de Filología Española, (en prensa).

Pérez de Moya, Juan, Filosofía secreta de la gentilidad, ed. Carlos Clavería, Madrid, Cátedra, 1991.

Quevedo, Francisco de, Epicteto y Phocílides, ed. José Manuel Blecua, Madrid, Castalia, 1981.

Quevedo, Francisco de, La cuna y la sepultura. Doctrina moral, ed. Celsa Carmen García Valdés, Madrid, Cátedra, 2008.

Quevedo, Francisco de, Prosa festiva completa, ed. Celsa Carmen García Valdés, Madrid, Cátedra, 2007.

Quevedo, Francisco de, Vida de santo Tomás de Villanueva, ed. Rafael Lazcano, Madrid, Revista Agustiniana, 2005.

Quevedo, Francisco de, Los sueños, ed. Ignacio Arellano, Madrid, Cátedra, 1999. Rico, Francisco, Nebrija frente a los bárbaros, Salamanca, Universidad de Salamanca, 1978.

39. Entre los autores coetáneos que manifestaron una idea de raigambre más claramente humanista, destaca Francisco Cascales, con su epístola «En alabanza de la gramática» incluida en la Década tercera de sus Cartas filológicas (1634, pero aprobadas en 1627); y antes de él también Vicente Espinel, quien se basa en argumentos de la misma naturaleza para tratar sobre los buenos preceptores en los libros I, 6 y i, 9 de su Marcos de Obregón (1617). Algunas otras sátiras contra el gramático, sobre todo contra el maestro de escuelas ignorante, aparecen también en los epigramas de las mismas Cartas filológicas, Década segunda, en versión latina traducidos al castellano (2, “Contra el gramático Antígenes», 19. “Contra un gramático que componía mal sus versos», 26, “Contra Oto»); y en un soneto de Bartolomé Leonardo de Argensola, sin fecha, “Contra un vecino suyo de gramática, gran voceador», «Pues no siempre tus rayos vengativos». 
Salas Barbadillo, Alonso Jerónimo de, Coronas del Parnaso y Platos de las Musas, Madrid, Imprenta del Reino, 1635.

Salas Barbadillo, Alonso Jerónimo de, Don Diego de Noche, Madrid, Viuda de Cosme Delgado, 1623.

Salas Barbadillo, Alonso Jerónimo de, La ingeniosa Elena, ed. Jesús Costa Ferrandis, Lérida, Instituto de Estudios Ilerdenses, 1985.

Salas Barbadillo, Alonso Jerónimo de, Obras, I. Corrección de vicios y La sabia Flora malsabidilla, ed. Emilio Cotarelo, Madrid, Tipografía de la Revista de Archivos, 1907.

Salas Barbadillo, Alonso Jerónimo de, Obras, II. El caballero puntual, ed. Emilio Cotarelo, Tipografía de la Revista de Archivos, Madrid, 1909.

Salas Barbadillo, Alonso Jerónimo de, La peregrinación sabia. El sagaz Estacio, ed. Francisco A. de Icaza, Madrid, Espasa-Calpe, 1958.

Salas Barbadillo, Alonso Jerónimo de, El tribunal de los majaderos, en Emilio Cotarelo, Colección de entremeses, loas, bailes, jácaras y mojigangas, desde fines del siglo XVI a mediados del XVIII, ed. José Luis Suárez y Abraham Madroñal, Granada, Universidad de Granada, 2000, vol. 1, pp. 257-261.

Simón Abril, Pedro, Gramática griega, Madrid, Pedro Madrigal, 1588.

Suárez de Figueroa, Cristóbal, Plaza universal de todas ciencias y artes, ed. Mauricio Jalón, Valladolid, Junta de Castilla y León, 2006, 2 vols.

Tirso de Molina, Cigarrales de Toledo, ed. Luis Vázquez Fernández, Madrid, Castalia, 1996. 



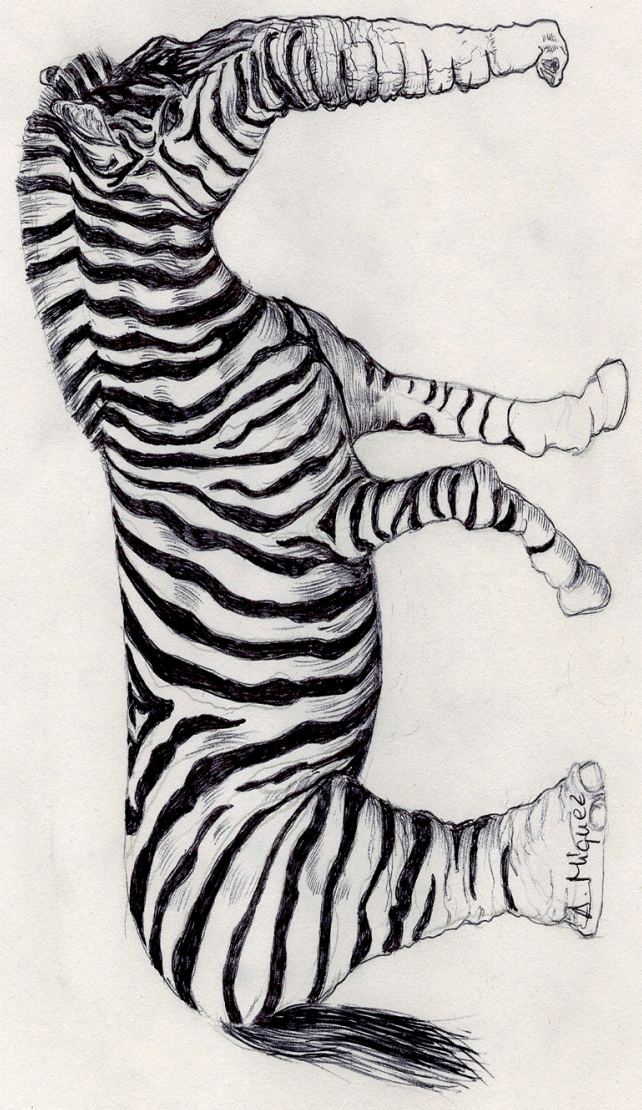


